\title{
PERFORMANCE EVALUATION OF PATH LOSS PARAMETERS FOR BROADCASTING APPLICATIONS
}

\author{
Pardeep Pathania ${ }^{1}$, Parveen Kumar ${ }^{2}$, Shashi B. Rana ${ }^{3}$ \\ ${ }^{I}$ Dept. of Electronics and Communication Enginerring, Beant College of Engineering and Technology, Gurdaspur \\ (Punjab) India \\ ${ }^{2}$ Dept. of Electronics and Communication Enginerring, Beant College of Engineering and Technology, Gurdaspur \\ (Punjab) India \\ ${ }^{3 *}$ Corresponding Author, Dept. of Electronics Technology, Guru Nanak Dev University Regional Campus, Gurdaspur
}

(Punjab) India

\begin{abstract}
In this research paper we investigated the effect of different path loss parameters with respect to distance in northen region of India (State: Punjab and Jammu) by using low and high power RF transmitter. In order to achieve good and reliable reception a practical broadcast engineers must know the suitability of appropriate model so as to design the various parameters of a transmitting station for achieving the high quality of signal at a known distance. In this paper we have taken field strength measurements for 100w FM and $10 \mathrm{KW} \mathrm{FM} \mathrm{station} \mathrm{at} \mathrm{almost} \mathrm{identical} \mathrm{distances}(50 \mathrm{Km})$ in different locations. All the measurements (readings) have been taken with the help of anritsu site master and by using the suitable anritsu dipole antenna. Comparative study of all graphs has been taken with respect to $F C C f(50,50)$ curves. In this paper, various investigations and their graphs have been plotted to show a comparative analysis of different parameters. In our measurements, we have used receiving antenna of 4 meter height and subsequent conversion has been applied to convert measurement (readings) into 9 meter receiving antenna height.
\end{abstract}

Keywords: Path loss, field strength, RF transmitted power, Receving antenna height, dipole antenna etc.

$$
\text { *** }
$$

\section{INTRODUCTION}

Computation of path loss is an essential element of the system design in any communication system. In radio and in TV broadcast system, estimation of the path loss is very significant as environment is continuously [1] changing with respect to time. Then question arises how to compute the path loss with utmost accuracy. Then its answer is by using the concept of propagation model. In the latest years, propagation models have been emerges as an active area of the study. A reliable propagation model is the one which estimate the path loss with the highest accuracy and with small standard deviation. This will help the telecommunication engineer to optimize the coverage area and use the [2] accurate transmitted power. This technique allow for the assessment of the path loss as a function of the distance, frequency, and transmitting antenna height for the fixed receiving antenna height. FCC $f(50,50)$ curves are intended for use in coverage forecast of broadcasting service in UHF and VHF band and are frequency independent, [3] so these can further be used for our comparative analysis for Fm applications. It must be noted that FCC $f(50,50)$ curve is intended for broadcasting service. It must be noted that these curve and original curve (FCC) were to be used for scheduling and planning of FM broadcast service in Punjab (Pathankot and Jammu) region of India. These curves were intended to be used by operational [4] and telecommunication engineers and hence allow the estimation of path loss \& electric field strength which were further be useful for various applications in outdoor communication system.

Path loss is an unwanted reduction in signal i.e field stength when propagating from transmitter to receiver Further, path loss will depend on antenna height, frequency, distance and on the environmental condition. Frequency and distance are to be taken into account in almost [5] every model. Accurateness of model in particular environment will depend on relational best fit between different parameter required by model and those existing for related area.

An extensive range of techniques have been developed over the years to calculate the coverage by using the propagation model. In general, propagation means broadcasting of the signal from the [6] transmitter to receiver. Empirical models uses existing equation obtained from the result of numerous measurement efforts. These models gives most precise result with ease of computational effot than deterministic models [7].

Objective of this present work is to study the variation of the received signal strength versus distance for the different location of the northern region of India (Punjab: Pathankot and Jammu). Similar work have been reported [8] in various 
countries (Korea, India, Spain and Canada) by Sang Ik park et al. (2007), Prasad et al. (2006), Arnida et al. (1999) and by Fogarty T. (2010). In some models frequency and transmitting antenna height and distance all are taken into accounts. A good practical engineer should know the variation of different parameters in order to optimize his system

\section{THEORATICAL BASIS}

Here in our investigation we have taken comparative study of FM band only. Comparison of different parameter has been made by refering the FCC $f(50,50)$ curve, which has been drawn for FM's channel number 2 to 6 at different distances and different transmitting antenna heights with fixed receiving antenna height of 9 meters. The observed signal strength values are then converted into path loss values using received power and gains of the transmitting and receiving antennas. These are reffered as observed path loss values. The path loss exponent i.e propagation constant from the observed path loss can be deduced as [9] follows :

Path loss is usually expressed as

$$
\mathrm{L}=\mathrm{L}_{0}+10 \mathrm{n} \log 10 \mathrm{~d}
$$

Where $\mathrm{d}$ is distance in meters

$\mathrm{L}_{0}$ is attenuation at $1 \mathrm{~m}$ in free space

$$
\text { Lo }=20 \log 10[4 \pi \mathrm{d} / \lambda]
$$

In logrithmic units it is given by

$$
\text { Lo }=32.45+20 \log \mathrm{fMHz}+20 \log \mathrm{d} \mathrm{km}
$$

Where $\mathrm{n}$ inrinsically embeds the effect of all the propagation mechnism: attenuation, diffraction, reflection etc. Equation (1) has been used for indoor as well as outdoor communication. As we know that it is not possible to quantify properly the individual effect of the scattering so the predictions obtained from the models are only the approximations [10].

In our discussion FCC $\mathrm{f}(50,50)$ curves has been used for comparative study because these curves have been in use effectively since numerous years by practising engineers and offers satisfactory estimation of field strength for enormous amount of practical cases. Such curves were developed using measured values taken in different geographical areas over different period of time and provide the medain values of field strength for service at 50\% of location during 50\% of time. As a result such curves shows the emperical values and not theoratical values.

In order to ascertain the dependence of propogation constant (n) with respect to distance and comparative analysis of our measurement with that of FCC $\mathrm{f}(50,50)$ curves, field strength values has been taken from FCC $\mathrm{f}(50,50)$ curves at transmitting antenna heights of $45 \mathrm{~m}$ and $100 \mathrm{~m}$ at different distances. The calculation of isotropic power from the field strength values [11] are given below :

$$
\mathrm{P}_{\text {iso }}=1 / 480\left(\mathrm{E}^{*} \lambda / \pi\right) 2 \text { Watts. }
$$

Here $\mathrm{E}$ is expressed in field strength in $\mathrm{v} / \mathrm{m}$

The values of $\mathrm{n}$ can easily obtained [10] as :

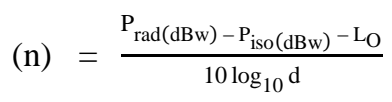

Where Lo has been defined previously.

The equivalent isotropic transmitted power $\mathrm{P}_{\mathrm{rad}}$ can be calculated after adding proper transmitting and receiving antenna gain.

$\mathrm{P}_{\mathrm{rad}}$ and $\mathrm{P}_{\mathrm{iso}}$ must be in the same unit i.e in $\mathrm{dBm}$ or $\mathrm{dBw}$.

The procedure to calculate the value of $\mathrm{n}$ from the FCC $f(50,50)$ curve is as (1) First read the field strength values for that particular transmitting antenna height at different distances. (2) By using above given formulas calculate the $\mathrm{P}_{\text {iso }}$ and then value of ' $n$ ' i.e. propagation constant.

The field strength values taken from FCC $\mathrm{f}(50,50)$ curve at various distances are converted into path loss in $\mathrm{dB}$ by using following relation :

Path loss $=$ Transmitted power + Transmitting antenna gain + Receiving antenna gain - Received power

This value of path loss is called as observed path loss at a given distance.

\section{EXPERIMENTAL DETAILS}

In order to realize our objective field strength measurements have been taken at two route (radii) i.e. from the Gurdaspur town by using the 100w FM radio transmitter which is operating at $100.1 \mathrm{Mhz}$ at transmitting antenna height of 45 meters and transmtting antenna gain of $2 \mathrm{~dB}$. Two different route (radii) chosen in order to measure the field strength in northen region of Punjab are given as under:

- Gurdaspur to Talwara (via Mukerian)

- Gurdaspur to Pathankot

Second field strength measurement have been taken with high power FM radio transmitter situated in northen region of India i.e. Kathua (Jammu) which is operating at $102.2 \mathrm{MHz}$ and transmitting antenna height is 100 meters. This station is transmitting RF power of $10 \mathrm{kw}$ at the antenna gain of $5 \mathrm{~dB}$. The field measurement for Kathua (Jammu) FM transmitter have been taken for only one route (radius) that is given below 
- Kathua (Jammu) to Dinanagar (Punjab) via Taragarh. For field strength measurements we used Anritsu site master and receiving antenna with isotropic gain of $2.15 \mathrm{~dB}$. In our measurements we have used receiving antanna of 4 meters height and subsequently suitable conversion have been applied to convert readings to 9 meters height receiving antenna. Since in FCC system all the readings has been taken by refering the FCC $\mathrm{f}(50,50)$ graph using 9 meter receiving antenna height. So a correction factor has been applied in order to convert the measured values to 9 meter receiving antenna height, as it is evidient that field strength varies linearly with respect to receiving antenna height. This is definitely a good aid to practical working engineer to have a quick idea for his system. From the measured values of field strength at various distances, the other parameters values such as propagation constant (n) and path loss in $\mathrm{dB}$ can be calculated.

\section{COMPARATIVE ANALYSIS OF THE DIFFERENT MEASUREMENTS}

In all the curves disscussed below we have used following notations for different stations highlighted as under:

Gsp - Gurdaspur

Tal - Talwara

Pkt - Pathankot

kth - Kathua

rec - Receiving

All FCC $f(50,50)$ curves discussed below signifies the estimated field strength value at the $50 \%$ of the potential receiver location at $50 \%$ of time when receiving antenna height is kept at 9 meter.

\subsection{Results and Discussion for Different Curves}

Field strength measurement data has been taken from the two different radii of Gurdaspur town (India: State: Punjab) and in one diection from Kathua town (India: State: Jammu) at respective distances (appr. $50 \mathrm{~km}$ ). Field strength values is then subsequently converted into received power, path loss in $\mathrm{dB}$ and propagation costant (n) using different formulas. From these values various graphs has been plotted. On observing various graphs carefully we conclude that variations of different parameters with distance are approximately follows FCC $f(50,50)$ curves. The noticeable difference in these graphs are that different parameters changes their behaviour as per the transmitted power and transmitting and receiving antenna heights .

It is observed from the various curves (below) that on changing the transmitting antenna height though the change in field strength is their but when transmitted power is increased or decreased $(100 \mathrm{w}$ or $10 \mathrm{kw})$ then we observe a significant change in the value of the field strength correspondingly.

\subsubsection{Field Strength Versus Distance Curve}

\section{Brief about the Implementation set up used and discussion of various results for figure 1}

First line from top i.e. uppermost line (violet color) in above graph shows the measurements (readings) of the field strength versus distance when moving from Kathua to Dinanagar (State: Punjab) for high power RF transmitter situated in Kathua (State: Jammu) upto distance of $50 \mathrm{~km}$. In this case Kathua (Jammu) RF transmitting station is operating at transmitted power of $10 \mathrm{kw}$, transmitting antenna height of $100 \mathrm{~m}$ and operating FM frequency of $102.2 \mathrm{MHz}$ respectively. Here all the measurements (readings) has been taken with $4 \mathrm{~m}$ receiving antenna height with the help of Anritsu site master. Suitable conversion (correction) factor has been applied for converting the measured value into $9 \mathrm{~m}$ receiving antenna height. In this case, the transmitting antenna gain is $5 \mathrm{~dB}$ refers to half wave dipole and hence suitably converted to to isotropic antenna by adding $2.15 \mathrm{db}$ gain to 5 $\mathrm{db}$ gain. Receiving antenna gain is $2.15 \mathrm{db}$ refer to isotropic antenna. In case of Second curve from top i.e. sky blue color the mesurements (reading) has been taken from FCC $\mathrm{f}(50,50)$ curve for transmitting antenna height of $100 \mathrm{~m}$ and transmitted power of $1 \mathrm{kw}$ with receiving antenna height of $9 \mathrm{~m}$. Third curve from top i. e. blue color the measurements (reading) have been taken from FCC $f(50,50)$ curve for transmitting antenna height of $45 \mathrm{~m}$ and transmitted power of $1 \mathrm{kw}$ with receiving antenna height of $9 \mathrm{~m}$. For the Red color curve and green color curve the mesurements (readings) haves been taken for Gurdaspur FM radio station operating at 100w power with transmitting antenna height of $45 \mathrm{~m}$. Antenna gain of 2 $\mathrm{db}$ refer to dipole so additional gain $2.15 \mathrm{db}$ has been added to make it equal to isotropic antenna. Receiving antenna used is of $4 \mathrm{~m}$ height and suitable conversion has been applied to convert the readings to $9 \mathrm{~m}$ receiving antenna. For the curve in red color measurements (readings) have been taken from Gurdaspur (Punjab) to Talwara (Punjab) while for the green color curve measurements (readings) have been taken from Gurdaspur to Pathankot area. 


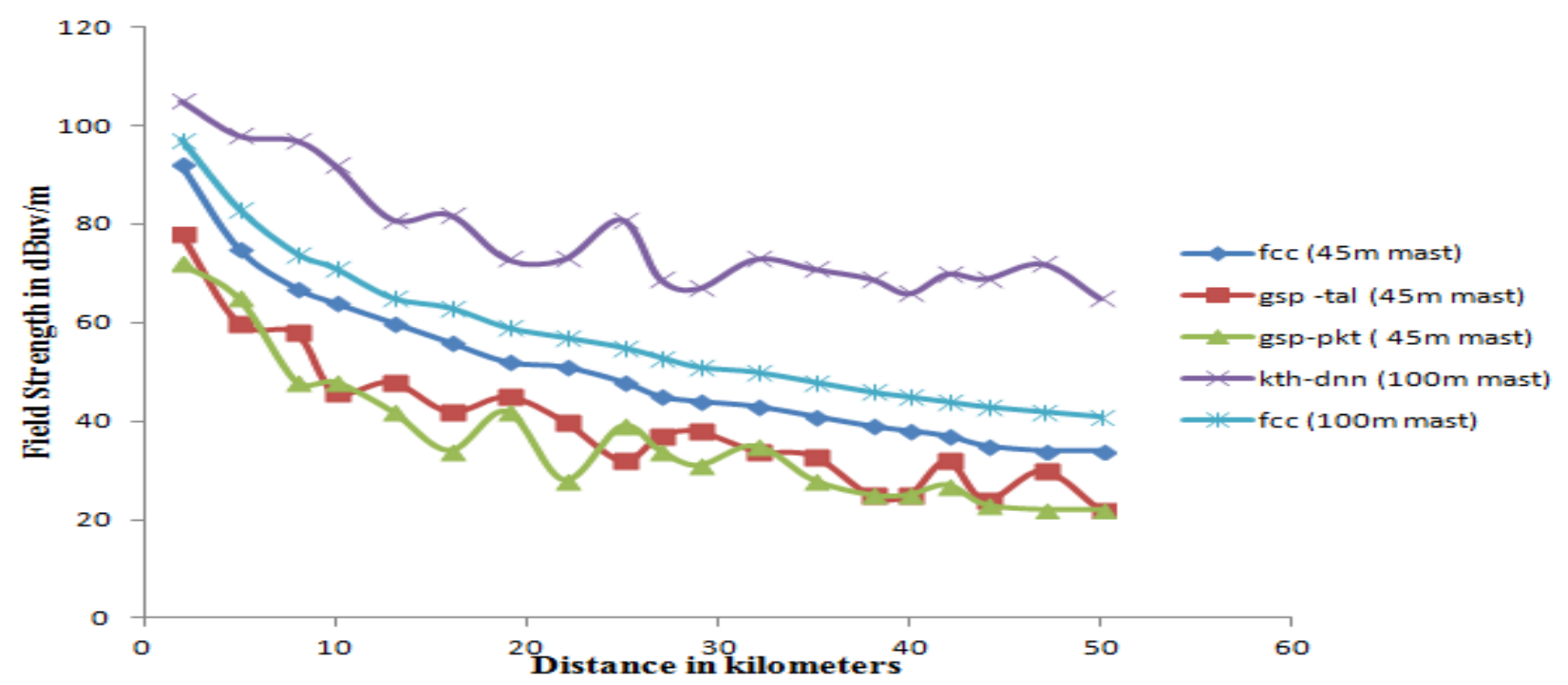

Fig. 1 Field Strength Versus Distance Curve

\section{Discussion and significance of all the curves in Figure} 1

Figure 1 shows that all the measurements follows almost the same slope i.e. in accordance with slope of FCC reference curve. It is evident that when transmitted power is more i.e 10 $\mathrm{kw}$ then there is a sharp increase in received field strength in comparision to the low power transmitted i.e $100 \mathrm{w}$. Again it is evident from two FCC mesurement curve at $45 \mathrm{~m}$ and 100 $\mathrm{m}$ transmitting antenna heights that when transmitted power remain same i.e. on increasing the transmitting antenna height corresponding effect on field strength is very less. On the other hand but when transmitting power is increased $(10 \mathrm{kw})$ then we get much increase in field strength correspondingly.
Further, when we plotted field strength versus distance curves of Gurdaspur $(100 \mathrm{w})$ station at two radii then we get almost same field strength in these two radii which confirms omni directional property of the transmitting antenna.

\subsubsection{Path Loss Versus Distance Curve}

Second objective of the research work is to study the variation of the path loss at the different location (Punjab: Pathankot, Jammu: Kathua) and its adjoining areas. In general, the path loss for antenna height of 9 meters is lower than antenna height of 4 meters due to the reduction of multipath effect by the use of higher antenna height

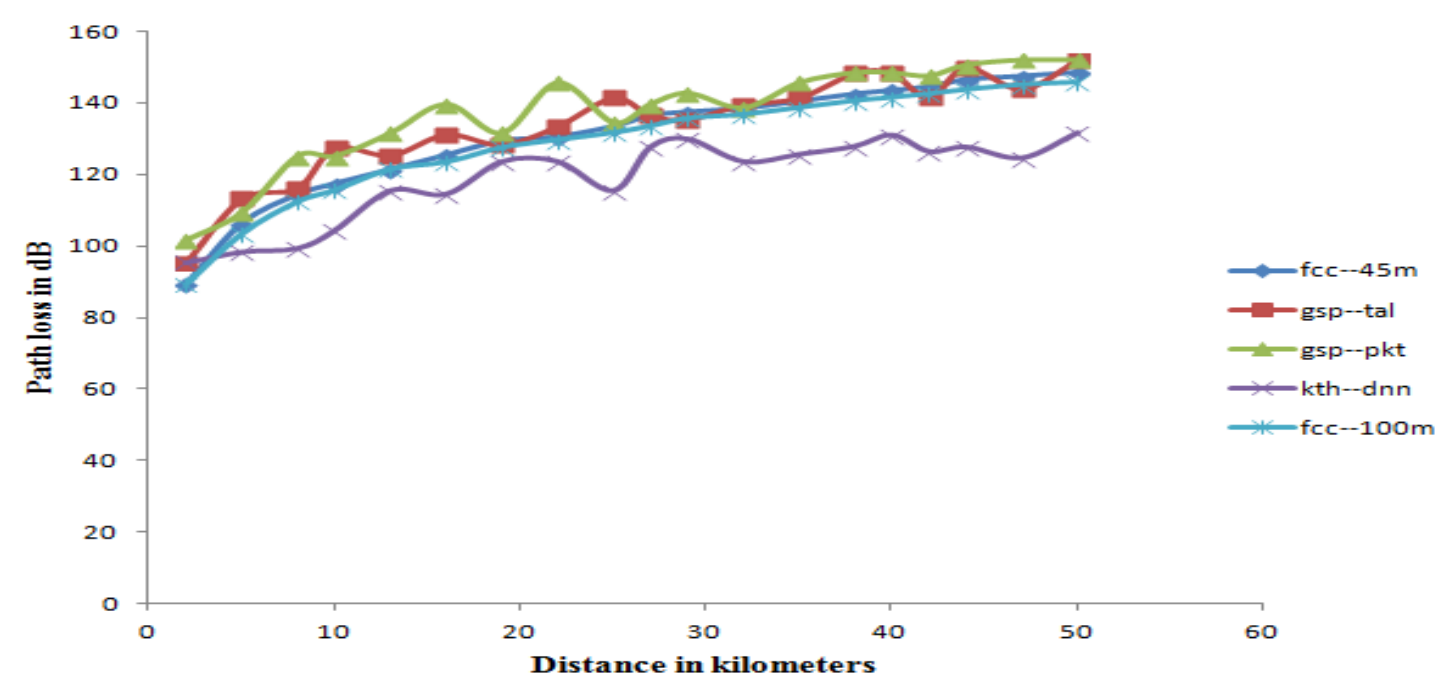

Fig. 2 Path Loss Versus Distance Curve 


\section{Brief about implementation set up for measurement}

\section{of path loss and results of Figure 2}

Variation of Path loss $(\mathrm{dB})$ with respect to distance $(\mathrm{kms})$ have been shown in figure 2. Uppermost curve (Green color) in figure 2 shows the change in value of path loss when moving from Gurdaspur (State : Punjab) to Pathankot (State: Punjab). We also observed the pathloss in second radii from Gurdaspur (State: Punjab) to Talwara (State : Punjab) as shown and highlighted in red color curve. Both measurements have been taken for Gurdaspur FM radio station operating at $100 \mathrm{w}$ power with transmitting antenna height of $45 \mathrm{~m}$. Blue and sky blue color curve shows that the mesurements (readings) taken from FCC $\mathrm{f}(50,50)$ curve. In the sky blue color curve mesurement of path loss versus distance have been implemented by using transmitting antenna height of $100 \mathrm{~m}$ and blue color curve for transmitting antenna height of 45 meter. For Violet color curve the measurements (readings) have been taken when moving from Kathua (Jammu) to Dinanagar (Punjab) in peripheral distance of $45 \mathrm{~km}$ by using high power RF transmitting $(10 \mathrm{kw})$ radio station Kathua at transmitting antenna height of $100 \mathrm{~m}$.

\section{Discussion and significance of all the curves in Figure} 2

Figure 2 signifies that path loss is almost same for two radii of measurements (readings) taken for Gurdaspur radio station (100w) i.e. red and green color curves shows variation of pathloss versus distance for (a) Gurdaspur to Talwara (b) Gurdaspur to pathankot. We also obsrve that when only antenna height is increased without increasing transmitted power then there is a very less change in path loss i.e almost same. However, when we take $10 \mathrm{kw}$ FM radio station i.e Kathua (Jammu) for $100 \mathrm{~m}$ transmitting antenna height then there is sharp decrease in value of path loss.

\subsubsection{Propagation Constant Versus Distance Curve:}

Third objective of present research work is study the variation of Propagation constant with respect to distance under varying condition (different transmitted power, different transmitting antenna height) as illustrated in fig. 3

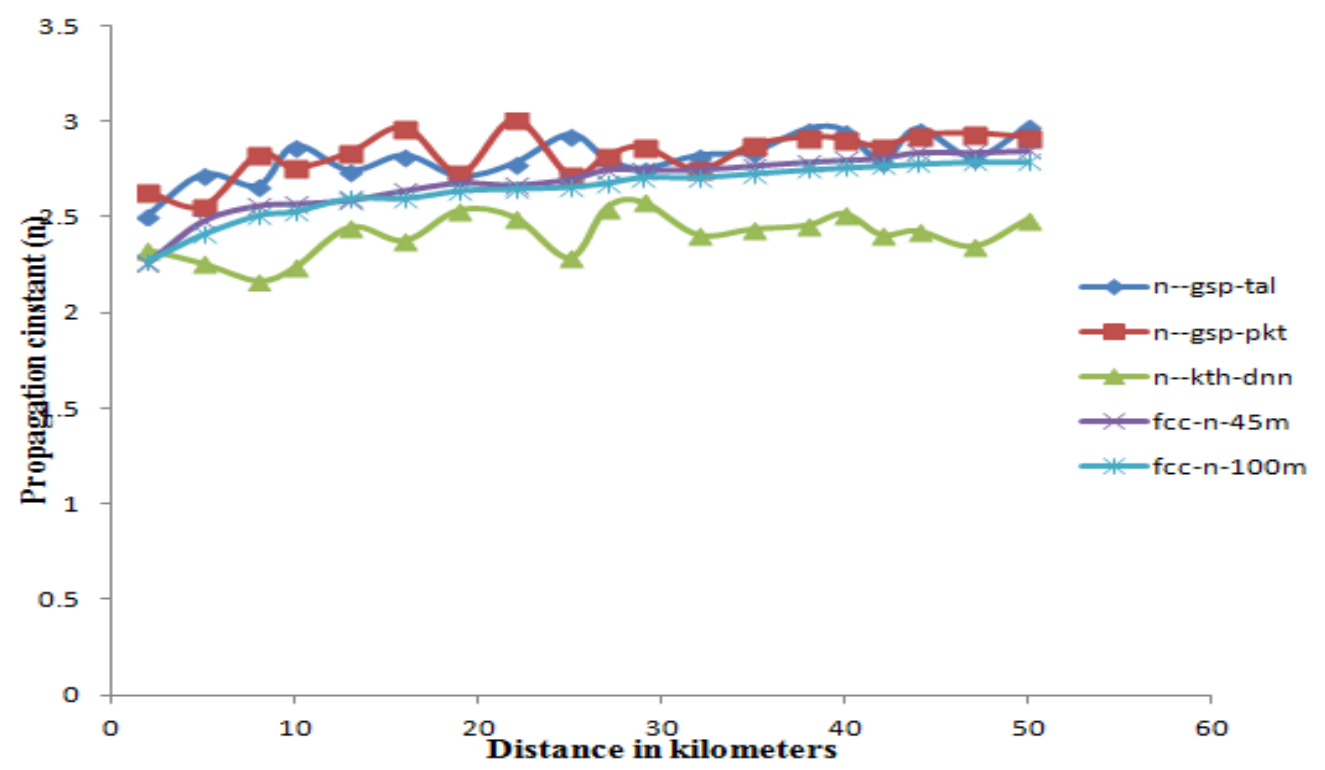

Fig. 3 Propagation Constant Versus Distance Curve

\section{Brief about implementation set up for measurement} of propogation constant (n) and results of Figure 3

In figure 3 Red and blue curves shows the variation of propogation constant (n) versus distance for Gurdaspur RF station operated at the $100 \mathrm{w}$ power. Both these curve shows that value of propagation constant almost remains same in two radii i.e. from (a) Gurdaspur to Talwara (b) Gurdaspur to Pathankot. Violet and sky blue color curve are from fcc graph. In this case sky blue color shows the variation of propogation constant (n) w.r.t. distance for $100 \mathrm{~m}$ transmitting antenna height and violet color shows the corresponding variation for $45 \mathrm{~m}$ transmitting antenna height. While Green color curve shows the variation in value of $\mathrm{n}$ for kathua (Jammu) FM radio station operating at $10 \mathrm{kw}$ transmitter power at antenna height of $100 \mathrm{~m}$. 


\section{Discussion and significance of all the curves in Figure}

\section{3}

The violet and sky blue color curve in figure 3 clearly shows the variation in FCC curve when transmitting antenna height has been changed as the RF transmitting power remains same i. e. $100 \mathrm{w}$. In that case there is a very small change in propagation constant (n). However, when RF power is changed i.e By using high power $(10 \mathrm{kw})$ kathua FM radio station at antenna height of $100 \mathrm{~m}$ then there is sharp decrease in value of propagation constant. Whereas by using low power (100w) Gurdaspur FM transmitter the value of propagation constant (n) start to increases in proportion.

\subsubsection{Propagation Constant Versus Distance Curve} for different receiving antenna heights

\section{Brief about implementation set up for measurement}

\section{of propogation constant (n) versus distance and}

\section{results of Figure 4}

In study of different parameters, next objective of our research work is to study the variation of propogation constant (n) w.r.t. distance $(\mathrm{kms})$. Propogation constant is the obstruction in path of signal flow due to effect of different phenomenon (reflection, refraction and scattering) during the propoagation of signal from one point to other.

\section{Discussion and significance of all the curves in Figure 4}

In the graph of figure 4 case study has been taken and illustrated by taking different receiving antenna height for low power RF transmitting antenna situated in Gurdaspur (Punjab) and high power RF transmitting antenna situated in Kathua (Jammu) region. Variation of propogation constant (n) w. r. t. distance $(\mathrm{km})$ is shown in figure 4 . Here in graph (plotted) Blue color curve is for $4 \mathrm{~m}$ and red color curve is for $9 \mathrm{~m}$ receiving antenna height for $\mathrm{FM}$ radio transmitter situated in Gurdaspur (Punjab). Green color curve is for $4 \mathrm{~m}$ and violet color for $9 \mathrm{~m}$ receiving antenna height for high power $(10 \mathrm{kw})$ FM transmitter situated in kathua (Jammu). We conclude from the figure 4 clearly that for small receiving receiving antenna height propagation constant is more and vice versa.

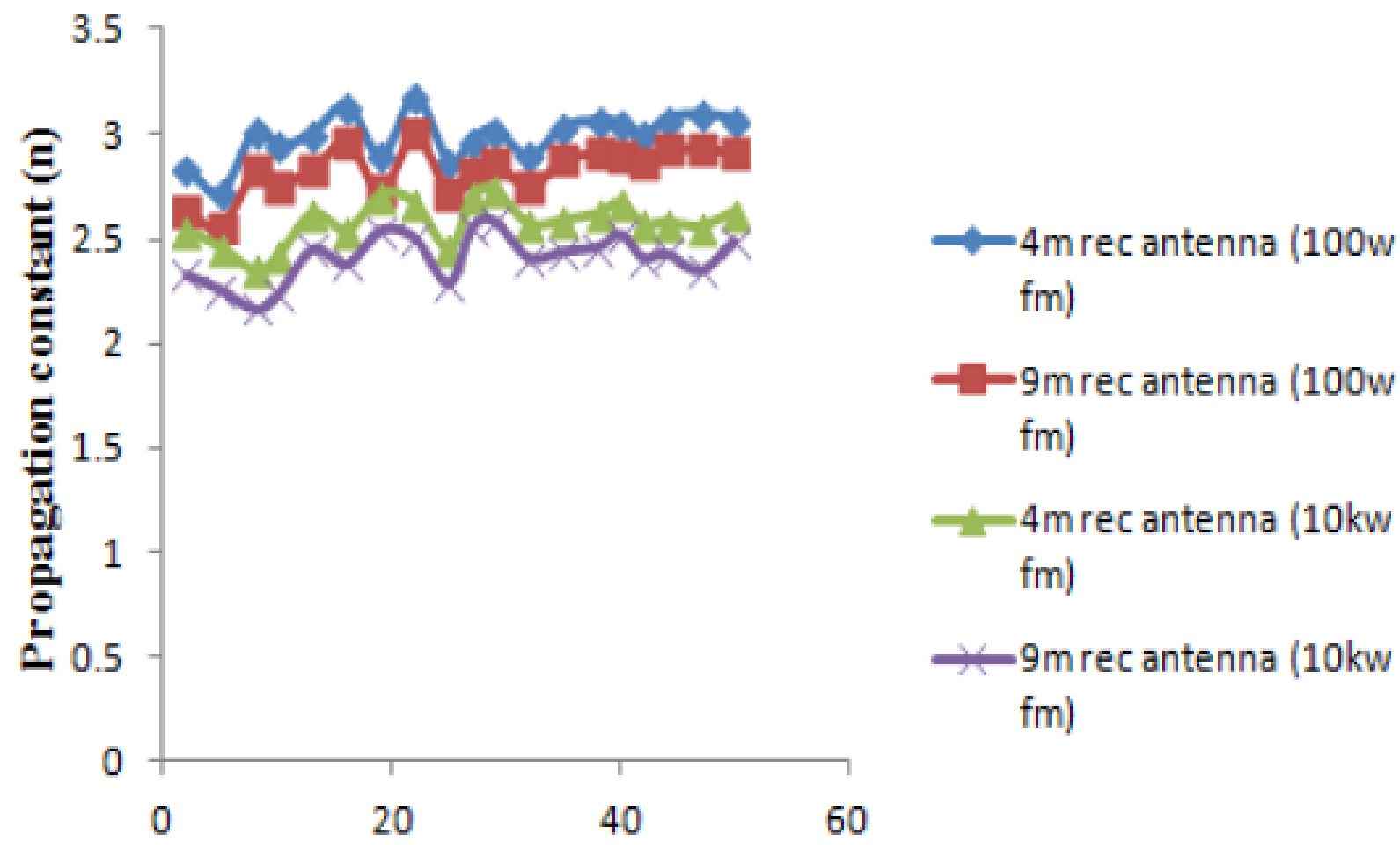

Distance in kilometers

Fig. 4 Propagation constant Versus Distance Curve 
Above graph shows how various parameters of path loss behaves when receiving antenna height is changed from $9 \mathrm{~m}$ to $4 \mathrm{~m}$ and vice versa respectively.

\subsubsection{Path loss Versus Distance Curve (Different} transmitting RF power, different transmitting antenna height and at different receiving antenna height) in figure 5

Brief about implementation set up for measurement of Path loss (dB) versus distance $(\mathrm{Kms})$ and results of Figure 5 path loss versus distance case study has been taken and illustrated by taking low power RF transmitting antenna (100 w) transmitter situated in Gurdaspur (Punjab) with lower transmitting antenna height (45 meters) and made corresponding comparative study by varying the receiving antenna of Anritsu master.

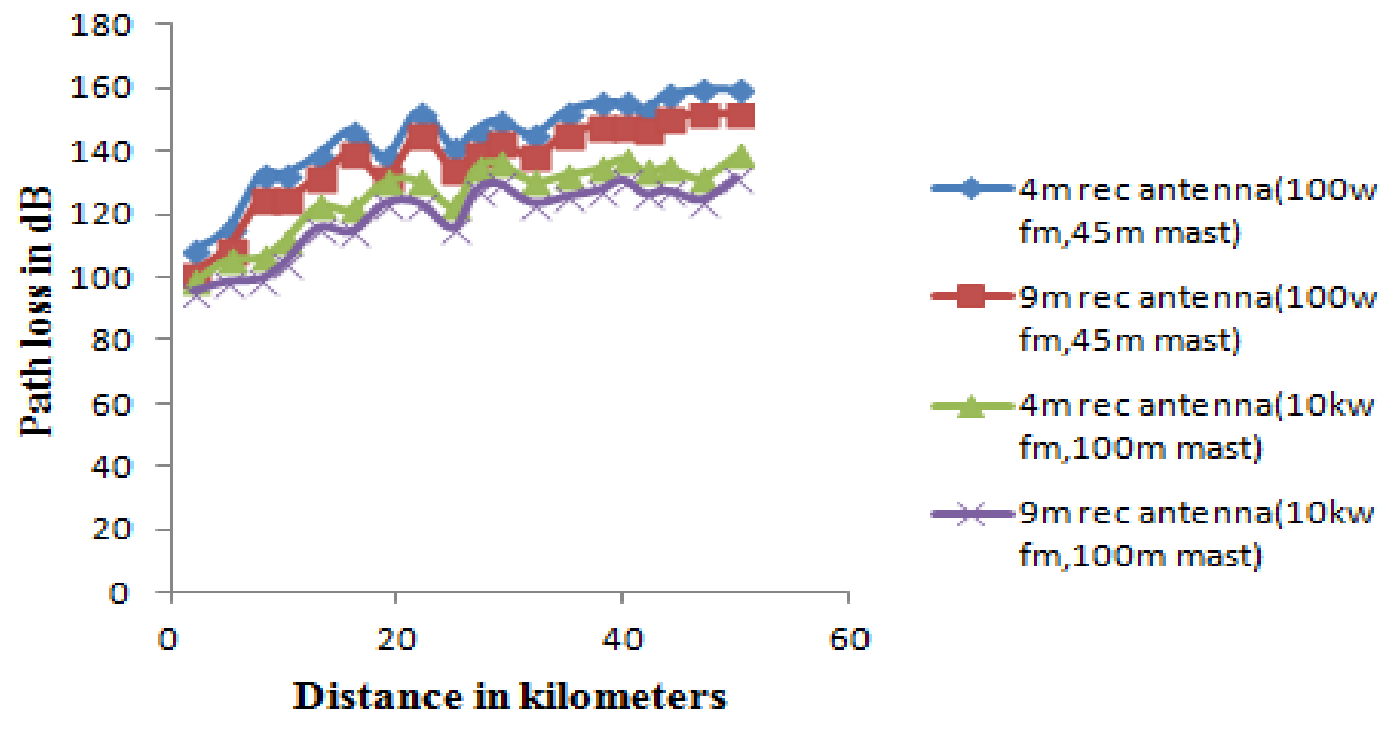

Fig. 5. Path loss Versus Distance Curve

\section{Discussion and significance of all the curves in Figure}

\section{5}

Figure 5 clearly shows that for low (100w) transmitting RF power (Gurdaspur) at transmitting antenna height (45 meters) the value of path loss is higher at lower receiving antenna height $(4 \mathrm{~m})$. While value of path loss is comparatively lower at higher receiving antenna height. Similar investigations have been made for higher RF power transmitting station situated in Kathua (Jammu) at transmitting antenna height for (a) 4 meter receiving antenna height (b) 9 meter receiving antenna height. Again value of path loss w. r. t. distance will be lower at 9 meter receiving antenna height than the 4 meter receiving antenna height. Color schematic will be same as discussed in earlier cases.

\subsubsection{Field Strength Versus Distance Curve (Different RF transmitted power, different mast height and at different receiving antenna height) Discussion and significance of all the curves in Figure 6}

Figure 6 clearly shows the field strength versus distance under different condition. Colors shematic in different graph will be the same as discussed above. This figure signifies that for smaller receiving antenna received field strength is less while bigger length receiving antenna has comparatively better signal strength. 


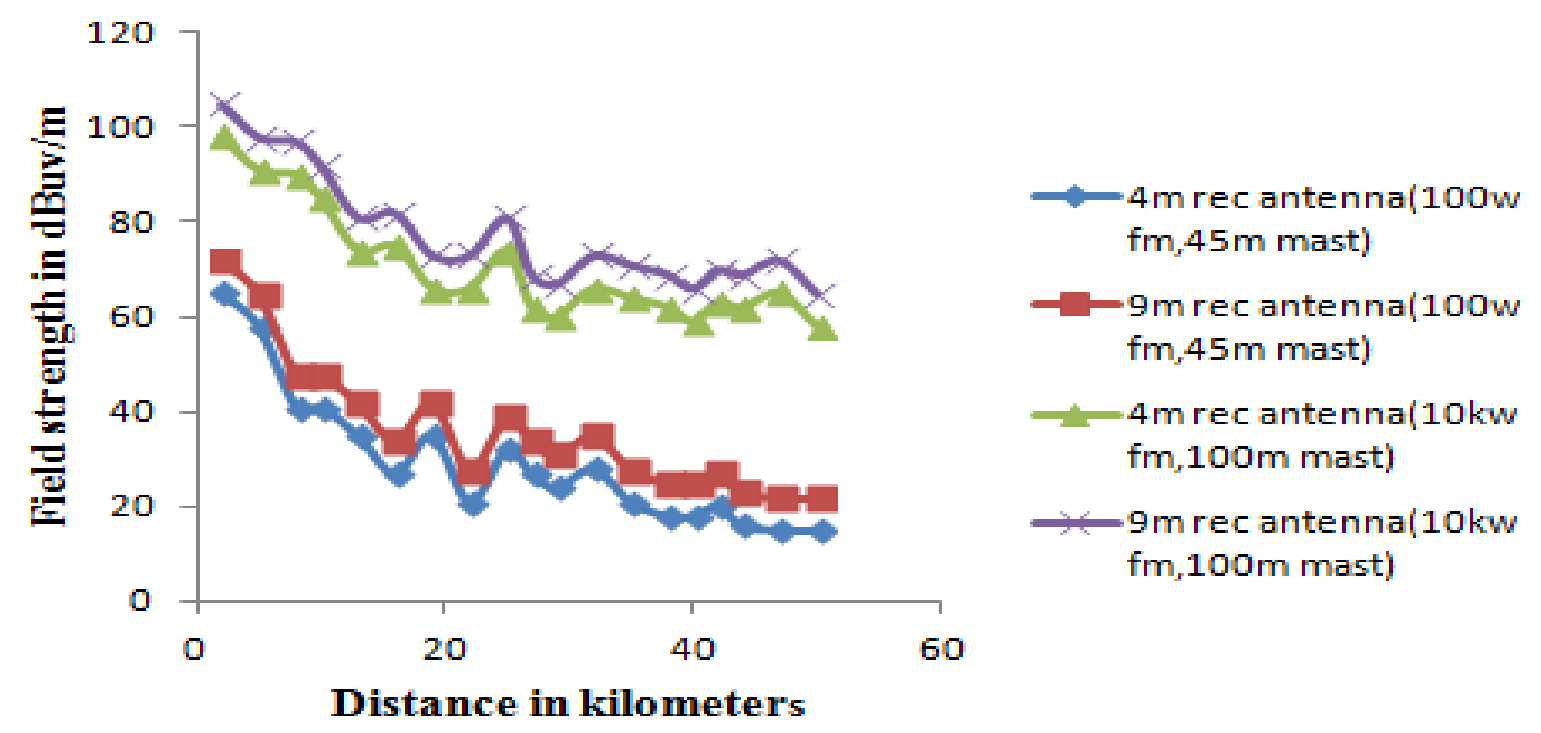

Fig 6 Field Strength Versus Distance Curve

So in broadcasting application received antenna height is most significant element for receiving good signal strength.

\section{CONCLUSIONS}

In our present research work we investigated the different parameters of path loss for $100 \mathrm{w}$ FM radio and $10 \mathrm{kw}$ FM radio for transmitting antenna heights of $45 \mathrm{~m}$ and $100 \mathrm{~m}$, for receiving antenna of $4 \mathrm{~m}$ and $9 \mathrm{~m}$ respectively. The comparative investigation has been carried out with the FCC models available in FCC $f(50,50)$ curve format for the ERP of $1 \mathrm{kw}$ and for different transmitting antenna heights at different distances (fixed receiving antenna of 9 meters). It is revealed from above discussion that when transmitting antenna height is changed (without changing transmitted power) then though there is variation in path loss parameters but on the other hand when transmited power is increased then we observe a significant changes in all the path loss parameters. Further, we observed that when receiving antenna height is varied from $4 \mathrm{~m}$ to $9 \mathrm{~m}$ and vice versa then all the parameters of path loss changes accordingly. Consequently as a result there is average increase in $7 \mathrm{~dB}$ path loss at different distances when receiving antenna height has been changed from 4 meters to 9 meters.

\section{REFERENCES}

[1] Armoogum,V. Soyjaudah, K. M. S. Mohamudally, N. and Fogarty, T., "Comparative Study of Path Loss with some Existing Models for Digital Television Broadcasting for Summer Season in the North of Mauritius at UHF Band", IEEE The Third Advanced
International Conference on Telecommunications (AICT-07), ISBN 0-7695- 2443-0.

[2] Prasad, M. V. S. N., "Path Loss Deduced From VHF and UHF Measurements Over Indian Subcontinent and Model Comparison", IEEE Transactions on Broadcasting, 52(3) (2006) 290.

[3] Federal Communications Commission, "Code of Federal Regulations", Title 47. Ch. 1, Part 73, Radio Broadcast Services Section. 73.683, 73.684 and 73.699.

[4] Perez-Vega, C. and Zamanillo, J. M., "Path Loss Model for Broadcasting Applications and Outdoor Communication Systems in the VHF and UHF Bands", IEEE Transactions Broadcasting, 48(2) (2002) 91.

[5] Armoogum, V. Soyjaudah, K.M.S. Mohamudally, N. and Fogarty, T. 2007, "Path Loss Analysis between the north and the south of Mauritius with some Existing Models for Digital Television Broadcasting for Summer Season at UHF Bands", Proceedings of the 8th IEEE AFRICON 2007, ISBN 0-7803-8606-X.

[6] http://www.radioelectronics.com/info/propagation/path -loss/rf-signal-loss tutorial. php.

[7] Armoogum, V. Soyjaudah, K. M. S. Mohamudally, N. and Fogarty, T. 2007, "Comparative Study of Path Loss with some Existing Models for Digital Television Broadcasting for Summer Season in the North of Mauritius at UHF Band", IEEE The Third Advanced International Conference on Telecommunications (AICT-07), ISBN 0-7695 - 2443-0.

[8] Hata, M., "Empirical formula for propagation loss in land mobile radio services", IEEETrans. Veh. Technol., 29(1980) 21. 
[9] Perez-Vega, C. and Garcia, J. L., "A simple approach to a statistical path-loss model for indoor communications", 27th European Microwave Conf. Proc. Jerusalem, 1997.

[10] Perez-Vega, C. and Zamanillo, J. M., "Path Loss Model for Broadcasting Applications and Outdoor Communication Systems in the VHF and UHF Bands", IEEE Transactions Broadcasting, 48(2) (2002) 91.

[11] Rama Rao, T. Vijaya Bhaskara Rao, S. Prasad, M. V. S. N. Mangal Sain, Iqbal, A. and Lakshmi, D. R., "Mobile Radio Propagation Path Loss Studies at VHF/UHF Bands in Southern India", IEEE Transactions On Broadcasting, 46(2) (2000) 158. 